Society may well excite their sympathy. A moment's consideration will show that the progress of horticulture is largely based on the correct application of scientific principles. What is not so familar to most people is the extent of the obligation under which science generally lies to horticulture. Should any reader require an illustration of this, let him turn to the "Origin of Species," and specially to the "Variation of Animals and Plants under Domestication." There is scarcely a page in the chapters of those volumes relating to plants that does not abound in references to the practices and the discoveries of horticulturists. Fertilization, cross-breeding, hybridization, selection, grafting, the limits and nature of variation, are only a few of the subjects on which horticulture furnishes the largest and in many respects the most trustworthy body of evidence yet available. That these subjec:s are studied, and that the experiments are made, not so much from a scientific as from a utilitarian point of view, is surely no matter of reproach. On the contrary, it is the business of horticulturists to act as they do, but without the aid of a Society much of the experience gained would be lost to science. All this might be admitted as a general principle, but yet its concrete application to the Royal Horticultural Society might be from various causes inappropriate. The Society in question has, however, distinct and undoubted claims to recognition for the good work it has done in science for a long period of years. The services it has rendered to science by its collectors, and the still greater value of its work in all departments of practical horticulture, should have secured for it more sympathetic and respectful treatment from its landlords. Among Societies deserving of national support and encouragement on the ground of public utility, there are few, indeed, that have greater claims than this. For years it has unfortunately been hampered by the necessity of providing amusement for a body of Fellows and visitors who cared nothing whatever for horticulture in its higher aims. Now there is a chance of the Society bursting its bonds and confining itself to its proper work $\rightarrow$ the promotion of scientific and practical horticulture. The plan of catering for fashionable idlers has proved disastrous. While horticulture proper was starved, and thousands upon thousands of pounds were utterly wasted, the landiords retain the whole of the property on which their tenants expended so much, and the Society has to seek a new home. In spite of all this, however, a valiant attempt has been made throughout long years of depression to maintain the scientific traditions of the Society. There has always been a small body of Fellows who have been mindful of the obligation which Thomas Andrew Knight, so long the President of the Society, imposed upon his successors. Lindley for forty year's maintained the scientific interests of horticulture in the Society, and he was assisted by Royle, by Bentham, and many others. Twenty years ago, or more, a Scientific Committee was appointed, an 1 this body, recruited by new accessions each year, still continues its labours. Under its guidance experiments have been performed in the Society's Experimental Garden at Chiswick; under its sanction have been published numerous Reports of very great scientific interest and importance; and much more might and could have been done but for the lack of means, or rather their diversion for more questionable purposes. The Committee in question consists of some twenty or thirty naturalists of all denominations--botanists, chemists, geologists, entomologists--associated with amateur and professional gardeners interested in science. To this body are referred for discussion and investigation the most varied objects of natural history and vegetable pathology ; before this body and its sister committees are brought all new introductions, whether of natural origin, or produced by the skill of the gardener, and which have any scientific interest. Sir Joseph Hooker is the Chairman of this Committee, the Rev. M. J. Berkcley was for many years its Secretary, and a large number of the most eminent biologists, chemists, and geologists have been or still are among its members, giving their services without fee or reward, simply in the interesis of scientific horticulture. On these grounds, therefore, the sympathy and co-operation of those interested in science may be claimed on behalf of the Royal Horticultural Society. A new programme has been decided on in principle, a new home must be provided at once, for the purpose of the Society's meetings and for housing the Lindley Library. This library, it may be added, is held in trust for the benefit of the Society, and is from time to time enriched by donations and by purchase, so far as the very meagre income of the Trustees permits. The donations would be much more numerous were it generally known that the library, though primarily intended for the Fellows, yet is under certain restrictions available to outsiders, so that, though housed in the Society's rooms, it cannot be sold or made away with in any financial catastrophe which might overtake the Society. Such a fate, however, seems to be averted at present ; the Society's debt is not large, and some members of the Council, or other friends, have made a good beginning by inaugurating a fund, to be used for the housing of the Society, so that ere long we may hope to see the old Society established on a more secure basis, and more potent than ever to advance those interests of science committed to its special keepin Maxwell T. Masters.

\section{Classification of Clouds.}

As one who has been engaged for nearly forty years in working up the materials for a monoyraph on clouds, I suppose I deserve the name of a "specialist in clouds" as much as any one. Yet I decline, for reasons which I will hereafter state in an appendix to my volume, to be altogether bound by the outlines of class:fication which my friends Prof. Hildebrandsson and the Hon. Ralph Abercromby appear to lay down (NATURE, December 8, p. I29 et seq. , although they adopt several of the names which come from my mint. I fully adopt the opinion implicitly held by Mr. Abercromby, and stated by my friend Captain Barker (ibid.) - from whose classification, however, I differ in one important point-that all ordinarily careful observers will readily comprehend the broad and simple distinctions expressed in any fairly good classification. Nevertheless, I believe that the apparently slow progress of this branch of research, and the tediousness of the work thrown upon the classifier, are matters on which we should congratulate our:elves, since every year adds something to our knowledge of those physical and structural processes which form the basis of all true classification; and I trust that some years may pass before an International Congress may attempt finally to set its seal upon any nomenclature or classification of clouds.

\section{Clement Ley.}

\section{Effect of Snow on the Polarization of the Sky.}

THE polarization of the sky has been shown experimentally by Tyndall and theoretically by Lord Rayleigh to be due to fine particles suspended in the atmosphere. According to both, the sunlight scattered at right angles to its original direction by very small particles is completely polarized in a plane through the sun. In observation, however, we find the light from a region of the sky distant $90^{\circ}$ from the sun is only partially polarized. This is due to that portion of the atmosphere being illuminated not merely by the sun, but also by the rest of the sky and the surface of the earth, and partly also no doubt to some of the particles not being sufficiently small compared with a wave-length. From these considerations we may expect that a fall of snow would cause a considerable diminution of the polarization. This expectation has been fulfilled in some recent observations of mine here at 6000 feet above sea-level. My polarimeter consists essentially of two piles of glass plates to depolarize the sky light; and a crystal and Nicol prism to test the depolarization. Owing to the strength of the polarization at this altitude, I find it necessary to use two piles of glass plates separated by two or three inches. This arrangement diminishes the number of double internal reflections, and so is a much more powerful polarizer or depolarizer than the same number of plates combined into one pile. As I have not seen this important practical consideration noticed before, I may point out that, in addition to the light refracted directly through the pile, there are a number of portions twice reflected. (One of these for instance is reflected first at the second surface of the last plate, and secondly at the first surface of the last plate. The number of such twice-reflected portions for $n$ plates is $n(2 n-\mathrm{I})$. When, as in my instrument, the fixed pile is much inclined, no light can reach the edge after being reflected first by one pile and then by the other. If the two piles were combined into one, I should have I 20 portions twice reflected ; as it is, I have only 60 . This increases the polarizing power of the instrument by at least one-third.

The crystal is a thick plate of Iceland spar cut so that the light passes along the optic axis. The fixed pile of three plates has its normal inclined at $47^{\circ}$ to the axis of the crystal. The movable pile of five plates has an index attached, which gives the inclination of its normal to the axis of the crystal. This inclination is the reading of the polarimeter. 